\title{
Differentiating Benign from Malignant Sinonasal Lesions: Feasibility of Diffusion Weighted MRI
}

\author{
Khaled M. El-Gerby ${ }^{1}$ Mohammad Waheed El-Anwar ${ }^{2}$ \\ 1 Radiodiagnosis Department, Faculty of Medicine, Zagazig University, \\ Zagazig, Egypt \\ 2 Department of Otorhinolaryngology Head and Neck Surgery, \\ Faculty of Medicine, Zagazig University, Zagazig, Egypt \\ Int Arch Otorhinolaryngol 2017;21:358-365.
}

Address for correspondence Mohammad Waheed El-Anwar, MD, Otorhinolaryngology Head and Neck Surgery Department, Faculty of Medicine, Zagazig University, Zagazig 0020552309843, Egypt (e-mail: mwenteg@yahoo.com; mwenteg1973@gmail.com).

\begin{abstract}
Keywords

- MRI

- nose

- tumor

- sinusitis

- CT scan

- magnetic resonance imaging

Introduction Appearance of nasal masses on routine CT and MRI are not pathognomonic. We utilized the apparent diffusion coefficient (ADC) value obtained from diffusion weighted image (DWI) to detect the differences in the microstructures of tumor and non-tumor tissues.

Objective The objective of our study was to evaluate the diagnostic role of DWI and $A D C$ values in differentiating between malignant and benign sinonasal lesions and its correlation with histopathological results as the reference standard.

Methods Patients with nasal and / or paranasal mass underwent CT, MRI, and DWI before any surgical intervention. We used diagnostic sinonasal endoscopy and biopsy to confirm the diagnosis after MRI.

Results When we used ADC value of $(1.2 \times 10-3 \mathrm{~mm} 2 / \mathrm{s})$ as a cut-off value for differentiating benign from malignant sinonasal lesions, we achieved $90 \%$ accuracy, $100 \%$ sensitivity, $88.4 \%$ specificity, $77.8 \%$ positive predictive value, and $100 \%$ negative predictive value. At this cut-off, benign lesions show statistically significant higher ADC value than malignant tumors.

Conclusion DW MRI and ADC value calculation are promising quantitative methods helping to differentiate between malignant and benign sinonasal lesions. Thus, they are effective methods compared with other conventional methods with short imaging time thus it is recommended to be incorporated into routine evaluations.
\end{abstract}

\section{Introduction}

Conventional MRI and CT are the chosen imaging modalities when evaluating head and neck cancers, unfortunately, the appearance of nasal masses on routine CT and MRI are not pathognomonic. Some benign lesions extend into adjacent structures mimicking malignancies. Additionally, routine imaging of the nasal masses does not allow pathological grading or distinguish between the various pathological types of nasal neoplasms. ${ }^{1}$

Diffusion weighted image (DWI) is a noninvasive technique which analyzes the structures of biologic tissues at a microscopic level. Apparent diffusion coefficient (ADC) value, ob-

received

August 14, 2016

accepted

October 6, 2016

published online

January 4, 2017 tained from DWI, has been utilized to detect the differences in the microstructures of tumor tissues and non-tumor tissues. ${ }^{2,3}$

The aim of this study was to evaluate the diagnostic role of diffusion weighted MRI and ADC values in differentiating between malignant and benign sinonasal lesions and its correlation with histopathological results as the reference standard.

\section{Patients and Methods}

This study took place in the departments of Radiodiagnosis and Otorhinolaryngology Head and Neck Surgery on patients with malignant and benign sinonasal lesions in the period

Copyright $\odot 2017$ by Thieme Revinter

Publicações Ltda, Rio de Janeiro, Brazil
License terms

(®) $\Theta \circledast$ 
from October 2011 to January 2015. We obtained informed written consent from the patients. We excluded from the study revision cases, patients from whom biopsies were taken or treated with radio- or chemotherapy prior to MRI, and patients with absolute contraindication to MRI, such as patients with cardiac peacemaker or aneurysmal clips.

Patients with nasal and / or paranasal mass were exposed to full history taken, nasal examination, and diagnostic endoscopy. They underwent CT and MRI before any surgical intervention. CT scan was axial and coronal non-contrast with 2-3 $\mathrm{mm}$ sections performed before surgical intervention. Diagnostic sinonasal endoscopy and biopsy was used to confirm the diagnosis after MRI.

\section{Radiological Assessment}

We performed radiological assessment comprising conventional pre- and post-contrast MRI.

\section{Instructions and Preparation of the Patients}

We asked patients to remove any ferromagnetic materials they might have on them, then fully explained the method of examination to patients before imaging and obtaining their consent. MR examination was performed at 1.5 tesla with a super conducting MR imager (Philips Medical Systems, Best, the Netherlands).

\section{Conventional MRI Technique Pre and Post Contrast}

We conducted the examination using standard circular head coils with small fields of view and thin sections while the patient was in supine position. We performed an initial scout T1-weighted sagittal view to act as a localizer of subsequent slices, and then used multiple pulse sequences to obtain axial images followed by coronal and sagittal images based on the location of the pathology.

We obtained T1-weighted images (WI) with a repetition time (TR) of 500-600 milliseconds and echo time (TE) of 10 milliseconds and obtained T2-weighted images with TR of 4500 milliseconds and TE of $100 \mathrm{~ms}$. The intersection gap was $1-2 \mathrm{~mm}$ and field of view (FOV) was generally $20 \times 25 \mathrm{~cm}$ with $256 \times 256$ matrix for axial images.

MRI protocol consisted of axial, coronal, and sagittal T1weighed, T2-weighted, and contrast enhanced T1-weighted images. We used IV Gadolinium diethylene triamine penta acetic acid (GD-DTPA) in a dose of $0.1-0.2 \mathrm{mmol} / \mathrm{kg}$ BW as a contrast in all patients.

\section{Diffusion Weighted MRI (DW- MRI) Examination Technique}

All patients underwent DW- MRI, which was obtained using multi-section single shot spin echo EPI sequences. Imaging parameters (TR/TE: 4285/108 milliseconds), FOV of $20 \times 25 \mathrm{~cm}$, acquisition matrix of $256 \times 256$, and section thickness of $5 \mathrm{~mm}$, with an interstice gap of 1-2 mm.

We applied diffusion-probing gradients in all three orthogonal directions ( $\mathrm{x}, \mathrm{y}$, and $\mathrm{z}$ ) with the same strength. We acquired images with a diffusion-weighted b-factor of 0.500 and 1000 seconds per $\mathrm{mm}^{2}$ to obtain a precise ADC map.
Apparent diffusion coefficient (ADC) maps were generated for all images with b-values of 500 and 1000 seconds per $\mathrm{mm}^{2}$.

The device automatically formed ADC maps with circular regions of interest $(\mathrm{ROI}) \sim 10 \mathrm{~mm}$ in diameter placed in the center of the lesion.

\section{Histopathological Analysis}

All patients were subjected to surgical or endoscopic biopsy and all specimens were sent to histopathology assessment. According to the histopathological analysis of the sinonasal lesions, masses were divided into benign (including inflammatory and benign tumors) and malignant.

\section{Statistical Analysis}

Statistical analysis was done using SPSS ("Statistical Package for Social Science") program version 16. The mean values for ADC were calculated for the each group. We used a one-way ANOVA test to compare results of more than two groups and Student's $t$-test to compare results between two groups. $\mathrm{P}$ value $<0.05$ was considered significant. We determined the ADC cut-off value for differentiating malignant from benign sinonasal lesions using the Kappa test. With confirmed benign lesions, we compared conventional T2 WI MRI to DWI and with confirmed malignant lesions; we compared post contrast images with DWI. We evaluated diagnostic accuracy of diffusion-weighted MRI in terms of sensitivity, specificity, accuracy, positive predictive value (PPV), and negative predictive value (NPV).

\section{Results}

This study included 24 patients with sinonasal masses. They were 8 women (33.3\%) and 16 men (66.7\%).Their ages ranged from 10 to 68 years with a mean of 38.5 years.

As for histopathology, the most common documented sinonasal diseases were inflammatory disease (12 cases, $50 \%$ ) then inverted papilloma (3 cases, $12.5 \%$ ), which represented the most common benign tumors followed by squamous cell carcinoma ( 3 cases, $12.5 \%$ ), which represented the most common malignant tumors (-Table $\mathbf{1}$ ).

According to MRI findings, most of inflammatory sinonasal diseases displayed low SI in T1 WI and high SI in T2 WI (-Fig. 1), except fungal infection, which displayed low signal void SI in T2 WI (-Fig. 2), and Wegner's granulomatosis, which displayed mixed SI in T2 WI. All MRIs showed a significant pattern of enhancement with the exception of mucocele, which showed faint peripheral enhancement, an important feature that helps differentiate it from sinonasal neoplasm. Most of sinonasal neoplastic cases displayed intermediate to low SI in T1WI and intermediate to high SI in T2 WI, except malignant melanoma, which displayed high SI in T1 WI and low SI in T2 WI. This may be due to hemorrhage and the paramagnetic effect of metals bound to melanin. All cases showed different patterns of enhancement (- Table $\mathbf{1}$ ).

Suggestive MRI criteria of malignant lesion were absent in two malignant lesions and found in other benign lesions with variable percentage up to $35.5 \%$ (-Table 2 ). 
Table 1 Histopathology of patients, MRI signal intensity, and pattern of enhancement of studied cases

\begin{tabular}{|c|c|c|c|c|c|c|}
\hline \multicolumn{2}{|l|}{ Histopathology } & \multirow{2}{*}{$\begin{array}{l}\begin{array}{l}\text { Number of } \\
\text { patients }\end{array} \\
4\end{array}$} & \multirow{2}{*}{$\begin{array}{l}\% \\
16.8\end{array}$} & \multirow{2}{*}{$\begin{array}{l}\text { T1 WI } \\
\text { Low (3 cases) } \\
\text { High (1 case) }\end{array}$} & \multirow{2}{*}{$\begin{array}{l}\text { T2 WI } \\
\text { High }\end{array}$} & \multirow{2}{*}{$\begin{array}{l}\text { Pattern of } \\
\text { enhancement }\end{array}$} \\
\hline $\begin{array}{l}\text { Inflammatory } \\
\text { disease }\end{array}$ & $\begin{array}{l}\text { Acute and } \\
\text { chronic sinusitis }\end{array}$ & & & & & \\
\hline & Sinonasal polyposis & 2 & 8.3 & $\begin{array}{l}\text { Mixed signal } \\
\text { mainly low }\end{array}$ & High & $\begin{array}{l}\text { Moderate } \\
\text { heterogeneous }\end{array}$ \\
\hline & Fungal sinusitis & 3 & 12.5 & Low & $\begin{array}{l}\text { Low ( } 2 \text { case) } \\
\text { Signal void (1 case) }\end{array}$ & $\begin{array}{l}\text { Moderate to } \\
\text { Marked }\end{array}$ \\
\hline & Mucocele & 2 & 8.3 & Low & High & Faint peripheral \\
\hline & $\begin{array}{l}\text { Wegner's } \\
\text { granulomatosis }\end{array}$ & 1 & 4.17 & Low & Mixed signal & $\begin{array}{l}\text { Marked } \\
\text { heterogeneous }\end{array}$ \\
\hline \multirow[t]{3}{*}{$\begin{array}{l}\text { Benign } \\
\text { tumors } \\
\text { ( } 5 \text { cases, } 20.7 \% \text { ) }\end{array}$} & Inverted papilloma & 3 & 12.5 & $\begin{array}{l}\text { Intermediate } \\
\text { to low SI }\end{array}$ & $\begin{array}{l}\text { Mixed area of } \\
\text { low and high SI }\end{array}$ & $\begin{array}{l}\text { Heterogeneous } \\
\text { (convulated } \\
\text { cribriform pattern) }\end{array}$ \\
\hline & Angiofibroma & 1 & 4.1 & Intermediate & Intermediate & Intense \\
\hline & Fibromyxoma & 1 & 4.1 & Intermediate & Intermediate & $\begin{array}{l}\text { Moderate } \\
\text { Homogenous }\end{array}$ \\
\hline \multirow[t]{5}{*}{$\begin{array}{l}\text { Malignant } \\
\text { tumors } \\
(7 \text { cases, 29.3\%) }\end{array}$} & $\begin{array}{l}\text { Squamous } \\
\text { cell carcinoma }\end{array}$ & 3 & 12.5 & Intermediate & $\begin{array}{l}\text { Intermediate } \\
\text { (1 case) } \\
\text { High (1 case) } \\
\text { Low (1 case) }\end{array}$ & $\begin{array}{l}\text { Mild } \\
\text { Homogenous ( } 1 \text { case) } \\
\text { Heterogeneous } \\
\text { ( } 2 \text { cases) }\end{array}$ \\
\hline & $\begin{array}{l}\text { Adenoid } \\
\text { cystic carcinoma }\end{array}$ & 1 & 4.17 & Intermediate & Intermediate & $\begin{array}{l}\text { Moderate } \\
\text { Homogenous }\end{array}$ \\
\hline & Esinthoneuroblastoma & 1 & 4.17 & Low & High & Heterogeneous \\
\hline & Lymphoma & 1 & 4.17 & Intermediate & Intermediate & Heterogeneous \\
\hline & Malignant melanoma & 1 & 4.17 & High & Low & Mild homogenous \\
\hline \multicolumn{2}{|l|}{ Total } & 24 & 100 & - & - & - \\
\hline
\end{tabular}

Abbreviation: WI, weighted image.

Conventional MRI diagnosed 8 cases of malignant lesion, 5 of them proved to be malignant while the other three were benign according to histopathological examination. On the other hand, MRI diagnosed 16 cases of benign lesion, of which 14 were benign, while the other two cases were malignant on histopathology.

Therefore, sensitivity, specificity, and accuracy of conventional MRI in differentiating between benign and malignant sinonasal lesions were $71 \%, 82 \%$, and $65 \%$, respectively, while

Table 2 MRI criteria suggestive of malignancy found in studied cases

\begin{tabular}{|l|l|l|}
\hline MRI criteria & $\begin{array}{l}\text { Benign } \\
\text { (inflammatory and } \\
\text { benign tumors) } \\
(N=17)\end{array}$ & $\begin{array}{l}\text { Malignant } \\
(N=7)\end{array}$ \\
\hline Unilateral sinus lesion & $6(35.5 \%)$ & $7(100 \%)$ \\
\hline Bone involvement & $4(23.5 \%)$ & $5(71.4 \%)$ \\
\hline Tumor necrosis & $1(5.8 \%)$ & $4(57.1 \%)$ \\
\hline Soft tissue mass & $2(11.7 \%)$ & $5(71.4 \%)$ \\
\hline Lymphadenopathy & $3(17.6 \%)$ & $5(71.4 \%)$ \\
\hline $\begin{array}{l}\text { Involvement of } \\
\text { surrounding structures }\end{array}$ & $4(23.5)$ & $5(71.4 \%)$ \\
\hline
\end{tabular}

positive predictive value (PPV) of conventional MRI was 62.5\% and negative predictive value (NPV) was $87 \%$ (-Table 3 ).

Most of the benign sinonasal lesions (15/17) 88.2\% appeared hypointense in $(b=500 \& 1000)$ DW images and hyperintense in ADC maps; however, two benign lesions (one was Wegner's granulomatosis and the other was inverted papilloma on histopathological examination) appeared hyperintense in $(b=500 \& 1000)$ DW images and showed restricted diffusion on ADC map (-Fig. 3), whereas all

Table 3 Sensitivity, specificity, accuracy, positive predictive value (PPV), negative predictive value (NGV) of conventional MRI and diffusion MRI in differentiating between benign and malignant sinonasal lesions

\begin{tabular}{|l|l|l|}
\hline $\begin{array}{l}\text { Diffusion weighted } \\
\text { MRI at 1.2 ADC cut-off value }\end{array}$ & $\begin{array}{l}\text { Conventional } \\
\text { MRI }\end{array}$ & \\
\hline $100 \%$ & $71 \%$ & Sensitivity \\
\hline $88.4 \%$ & $82 \%$ & Specificity \\
\hline $90 \%$ & $65 \%$ & Accuracy \\
\hline $77.8 \%$ & $62.5 \%$ & PPV \\
\hline $100 \%$ & $87 \%$ & NPV \\
\hline
\end{tabular}



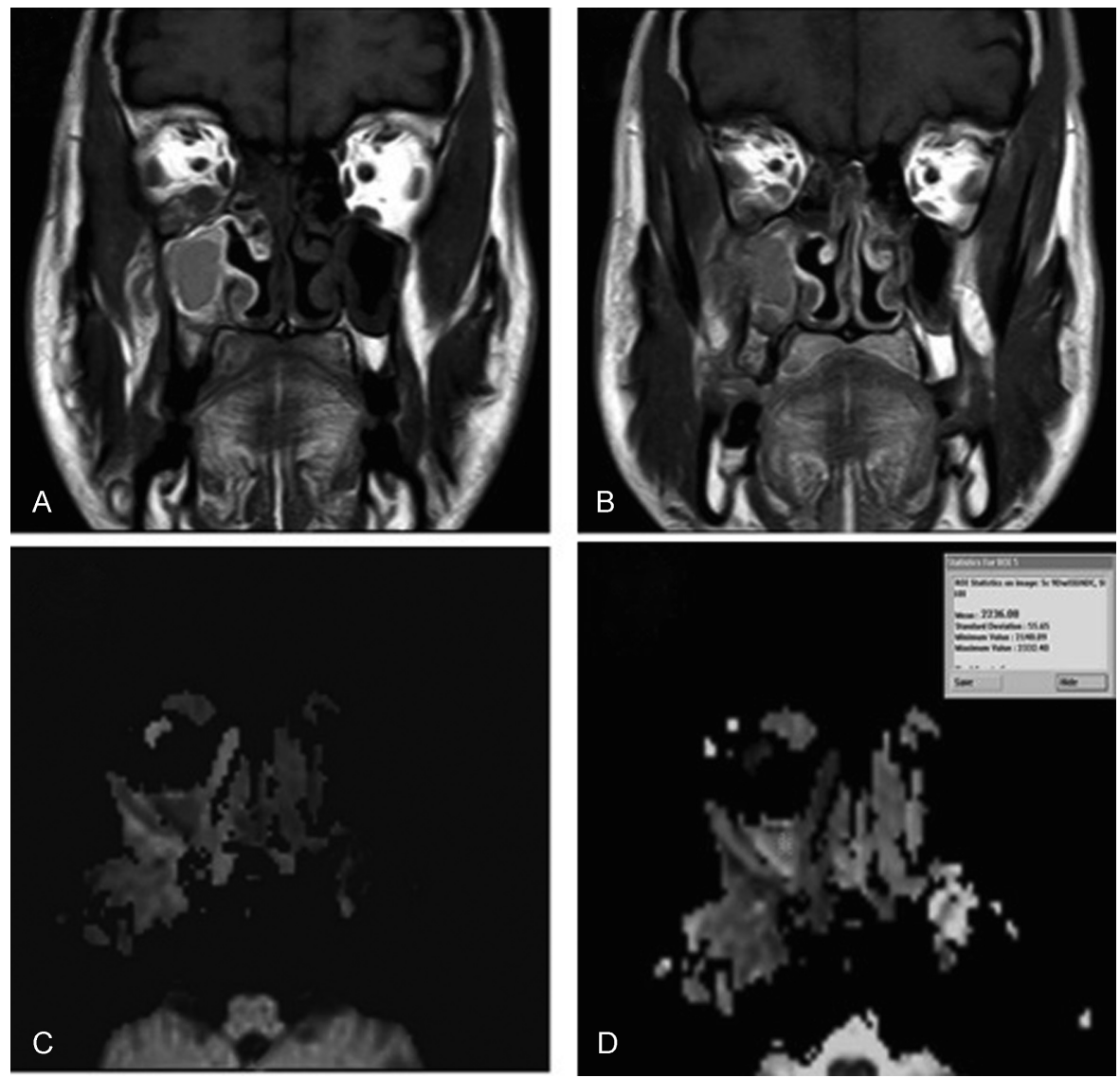

Fig. 1 Inflammatory sinusitis. (A, B) Coronal T1WI and Coronal T1W gadolinium-enhanced MR images reveal faint enhancement of the lesion that destroys the lateral wall of maxillary sinus extending into temporalis muscle with infra temporal extension, and roof of maxillary sinus extending into orbital floor obliterating high SI of orbital fat produce orbital cellulitis. (C) Axial DW image with b-value of 1000 second/mm² shows low signal intensity of the lesion denoting facilitated diffusion. (D) Axial ADC map image with b-value of 1000 second $/ \mathrm{mm}^{2}$ shows high signal intensity of the lesion denoting facilitated diffusion with ADC value is $2.2 \times 10-3 \mathrm{~mm}^{2} / \mathrm{s}$. DWI \& ADC value readings suggestive of benign lesion.

malignant sinonasal lesions (7/7) appeared hyperintense in $(b=500$ \&1000) DW images and hypointense in ADC maps. Malignant sinonasal lesions had lower mean ADC value than benign lesions (-Fig. 4), this difference was highly statistically significant $(p<0.0001)$ ( - Table 4$)$.
Diffusion Weighted MRI at ADC cut-off value of 1.2 had higher sensitivity, specificity, accuracy, PPV, and NPV than conventional MRI in differentiating between benign and malignant sinonasal lesions with high significant difference $(p<0.0001)$ ( - Table 3 ).

Table 4 Diffusion-weighted MRI findings for the studied sinonasal lesions

\begin{tabular}{|c|c|c|c|}
\hline & $\begin{array}{l}\text { Benign } \\
\text { (inflammatory and benign tumors) } \\
(N=17)\end{array}$ & $\begin{array}{l}\text { Malignant } \\
(N=7)\end{array}$ & $p$ \\
\hline \multicolumn{4}{|c|}{ Signal intensity on images $(b=500 \& 1000)$} \\
\hline Hyperintense & $2(11.8 \%)$ & $7(100 \%)$ & \multirow[t]{2}{*}{-} \\
\hline Hypointense & $15(88.2 \%)$ & 0 & \\
\hline \multicolumn{4}{|c|}{ Signal intensity on ADC maps } \\
\hline Hyperintense & $15(88.2 \%)$ & 0 & \multirow[t]{2}{*}{-} \\
\hline Hypointense & $2(11.8 \%)$ & $7(100 \%)$ & \\
\hline Range & $1.31 \times 10^{-3} \mathrm{~mm}^{2} / \mathrm{s}$ to $2.72 \times 10^{-3} \mathrm{~mm}^{2} / \mathrm{s}$ & $0.82 \times 10^{-3} \mathrm{~mm}^{2} / \mathrm{s}$ to $\left.1.27 \times 10^{-3} \mathrm{~mm}^{2} / \mathrm{s}\right)$ & \\
\hline Mean & $1.73 \times 10^{-3} \mathrm{~mm}^{2} / \mathrm{s}$ & $0.05 \times 10^{-3} \mathrm{~mm}^{2} / \mathrm{s}$ & $p<0.0001$ \\
\hline
\end{tabular}



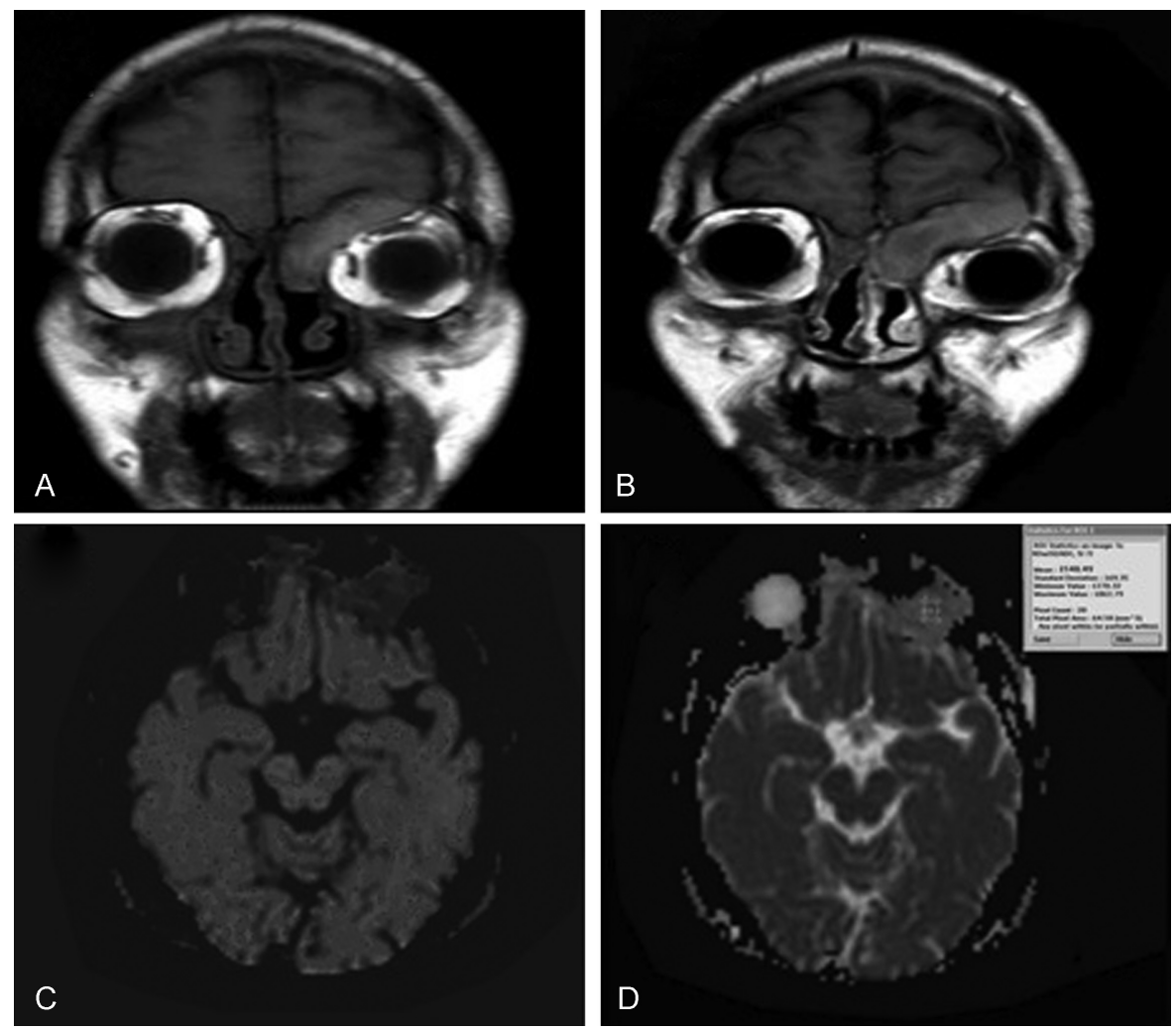

Fig. 2 Fungal sinusitis. (A, B) Coronal T1WI and Coronal T1W gadolinium-enhanced MR image reveals intense enhancement of the lesion and thick uniform peripheral enhancement of left and right subperiosteal orbital abscess. (C) Axial DW image with b-value $1000 / \mathrm{mm}^{2}$ shows low signal intensity of the lesion denoting facilitated diffusion. (D) Axial ADC map image with b-value of $1000 \mathrm{~second} / \mathrm{mm}^{2}$ shows relatively high signal intensity of the lesion denoting facilitated diffusion with $A D C$ value is $1.7 \times 10-3 \mathrm{~mm}^{2} / \mathrm{s}$. Readings suggestive of benign lesion.

\section{Discussion}

A broad spectrum of benign and malignant tumors and inflammatory lesions can affect the sinonasal region. ${ }^{4}$ Maxillary sinus squamous cell carcinoma (SCC) is the most common sinonasal malignancy. Small round blue cell tumors such as olfactory neuroblastoma, malignant melanoma, neuroendocrine carcinoma, and lymphoma may be difficult distinguish from SCC and from benign and inflammatory lesions. ${ }^{5}$

The DWI is a noninvasive technique that is promising in differentiation between benign and malignant sinonasal masses and evaluating their functional activity based on the random translational motion of water protons, indirectly proportional to the diffusion barriers. ${ }^{2}$ Structural changes in the tissues (benign or malignant) may result in different signals on DWI, which could be quantified by measuring the $A D C$ values. The $A D C$ value represents an objective parameter reflecting the tissue-specific diffusion capacity, which has already being used for tissue characterization and follow-up measurements. ${ }^{2}$

Generally, because malignant tumors have hyper cellular structure and enlarged nuclei, their water diffusion is restricted. Thus, low ADC values in malignant tissues could be attributed to the increase cellularity, restriction of intracellular distance, and water diffusion restriction. Studies have reported that $\mathrm{ADC}$ values are related to the cellular density and mass secretion properties. ${ }^{6,7}$
Water constitutes $95 \%$ of sinonasal secretions, hence MRI SI of acutely inflamed mucosa are similar to water in their low SI in T1 WI and high SI in T2 WI, while chronic secretions vary in fluid and protein content, resulting in an increase of T1 WI signal from low to high and decrease in T2 WI signal from high to low. ${ }^{8}$ MRI findings in fungal sinusitis depend on the high content of calcium, iron, and magnesium within fungal hyphae. Both iron and magnesium cause relevant shortening of $\mathrm{T} 1$ and $\mathrm{T} 2$ and therefore appear as hypointense signal void lesions filling sinonasal cavity ${ }^{3}$ with significant pattern of enhancement. ${ }^{11,12}$

This was in agreement with our results, where most of inflammatory sinonasal diseases displayed low SI in T1 WI and high SI in T2 WI except for fungal infection, which displayed low SI (2 cases), signal void in one case, and Wegner's granulomatosis displaying mixed SI. All showed significant pattern of enhancement of varying degree (mildmoderate-marked) except mucocele, which showed faint peripheral enhancement.

MRI signal intensity and enhancement pattern in sinonasal tumors are nonspecific. Nonetheless, some tumors have specific MRI features that generally render a reliable diagnosis. This is the case with inverted papilloma, characterized by convoluted cribriform pattern or septate striated appearance, diagnosed by mixed SI of both edematous stroma (high SI) and epithelium (low SI), as well as angiofibroma, characterized by intense enhancement. Malignant tumors show 

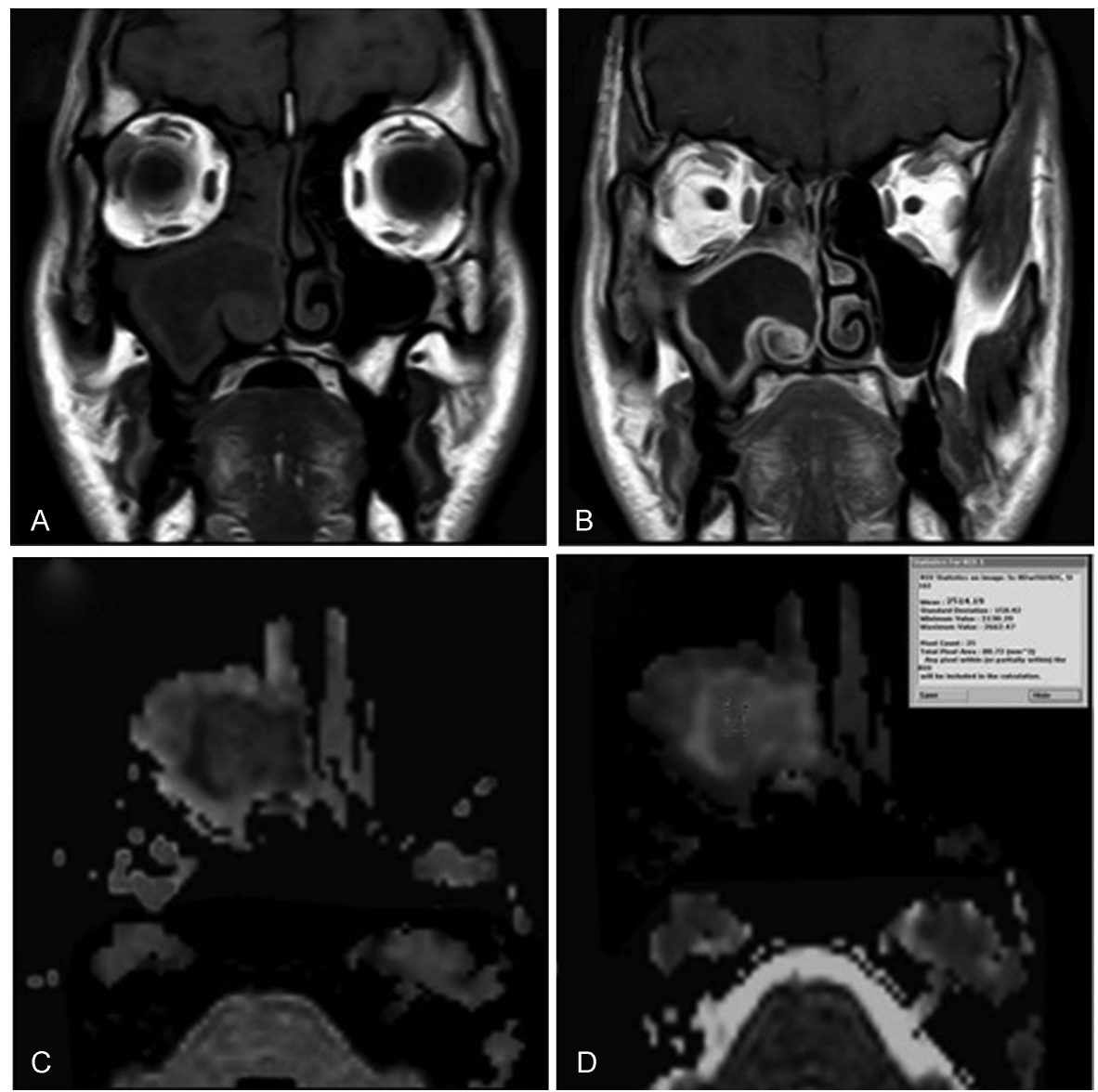

Fig. 3 Inverted papilloma case. (A, B) coronal T1WI \& coronal T1W gadolinium-enhanced MR images show heterogeneous enhancement of the lesion "well enhancing stroma and less enhancing epithelium that create convulated cribriform pattern." (C) Axial DW image with b- value 1000 second $\mathrm{mm}^{2}$ shows low signal intensity of the lesion denoting facilitated diffusion. (D) Axial ADC map image with b-value of $1000 \mathrm{~second} / \mathrm{mm}^{2}$ shows high signal intensity of the lesion denoting facilitated diffusion with ADC value is $1.51 \times 10-3 \mathrm{~mm}^{2} / \mathrm{s}$.

variable SI in both $\mathrm{T} 1$ and $\mathrm{T} 2$ with variable enhancement pattern depending on tumor cellularity and necrosis. ${ }^{3}$

This matches our results, where all cases presented the characteristic cribriform pattern of inverted papilloma and angiofibroma exhibited intense enhancement. On the other hand, malignant cases displayed intermediate to low SI in T1 WIs ( 6 cases) and intermediate to high SI in T2 WIs, except one case that pathologically proved to be malignant melanoma and displayed high SI in T1 WI and low SI in T2WI. This may be attributed to hemorrhage and paramagnetic effect of metals bound to melanin. ${ }^{9,10}$ Additionally, all malignant cases exhibit different patterns of enhancement, which was homogenous in four cases and heterogeneous in three.

In our study, MRI criteria suggestive of malignancy were unilateral sinus lesion, bone involvement, tumor necrosis, soft tissue mass, lymphadenopathy, and involvement of surrounding structures. These criteria were matched with Maeda et al. ${ }^{3}$ We found that these criteria were absent in two malignant cases and found some of these criteria in benign cases, with variable percentage up to $35.5 \%$. According to these criteria, when we used conventional contrast-enhanced MRI alone correlated with histopathological findings, sensitivity and specificity of conventional contrast-enhanced MRI in the differentiation between benign and malignant sinonasal lesions were $71 \%$ and $82 \%$, respectively.

Then, with the introduction of DWI with MRI, diagnostic accuracy improved the differential diagnosis between benign and malignant sinonasal lesions. ${ }^{2,11}$

In this study, we evaluated the potential of using echoplanar diffusion weighted MRI in the characterization of sinonasal lesions by determining their ADC values using b-values of 500 and 1000 second per $\mathrm{mm}^{2}$. The signal intensity of the sinonasal lesions in DW images and ADC maps varied according to histopathological type of sinonasal lesion. The evaluation with DWI showed that benign sinonasal lesions, including both inflammatory and benign tumors, appeared hypointense in $(b=500,1000)$ DW images and hyperintense in ADC maps, while malignant sinonasal lesions were hyperintense on $(b=500,1000)$ DW images and hypointense in ADC maps.

In our study, the overall mean ADC value for malignant sinonasal tumors was $1.05 \times 10-3 \mathrm{~mm}^{2} / \mathrm{s}$ and ranged from $0.82 \times 10-3 \mathrm{~mm}^{2} / \mathrm{s}$ to $1.27 \times 10-3 \mathrm{~mm}^{2} / \mathrm{s}$, which was lower than the mean ADC value of both benign tumors and inflammatory lesions (mean $=1.73 \times 10^{-3} \mathrm{~mm}^{2} / \mathrm{s}$, range; $1.31 \times 10^{-3} \mathrm{~mm}^{2} / \mathrm{s}$ to $2.72 \times 10^{-3} \mathrm{~mm}^{2} / \mathrm{s}$ ). This difference 

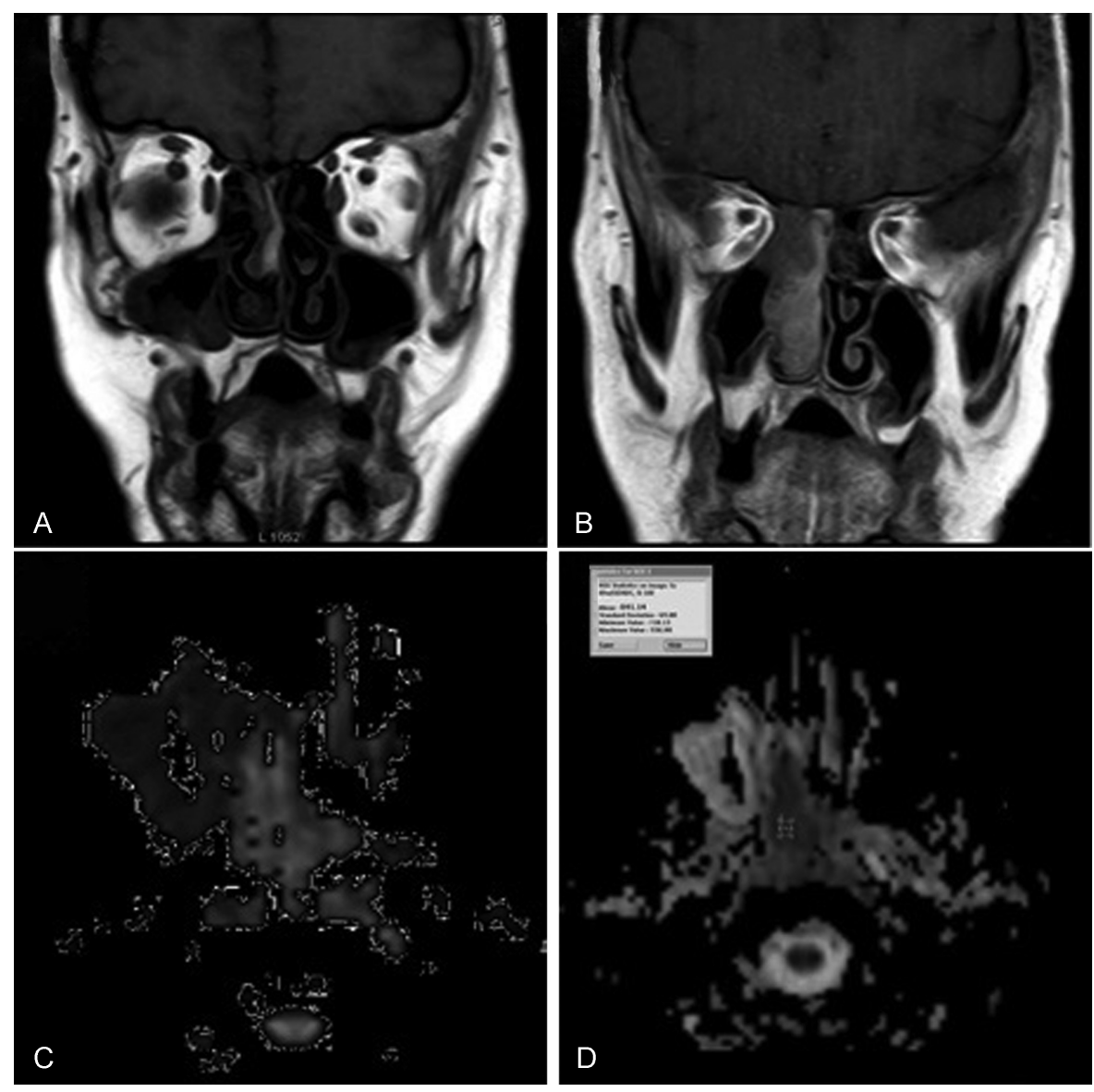

Fig. 4 Malignant melanoma case. (A, B) Coronal T1WI Coronal T1W gadolinium-enhanced MR images reveal mild homogenous enhancement of the mass. (C) Axial DW image with b-value 1000 seconds $/ \mathrm{mm}^{2}$ shows high signal intensity of the lesion denoting restricted diffusion. (D) Axial ADC map image with b-value of 1000 second $/ \mathrm{mm}^{2}$ shows low signal intensity of the lesion denoting restricted diffusion with ADC value of $0.84 \times 10-3$ $\mathrm{mm}^{2} / \mathrm{s}$. DWI \& ADC value readings suggestive of malignant lesion.

was highly statistically significant. These results agreed with Sasaki et al, ${ }^{10}$ White et al, ${ }^{12}$ and Razek et al. ${ }^{13}$

The mean ADC value for inflammatory lesions ranged from $1.54 \times 10^{-3} \mathrm{~mm}^{2} / \mathrm{s}$ to $2.72 \times 10^{-3} \mathrm{~mm}^{2} / \mathrm{s}$, while that of benign tumors ranged from $1.310^{-3} \mathrm{~mm}^{2} / \mathrm{s}$ to $1.810^{-3} \mathrm{~mm}^{2}$ / $s$ and there was no statistical difference in ADC value differentiation between inflammatory lesions and benign tumors. These results are in agreement with those of Sasaki et al. ${ }^{10}$

Although we could not significantly differentiate between different benign tumors on basis of ADC value measurement, we found that benign vascular tumor as juvenile angiofibroma had higher ADC value $\left(1.810^{-3} \mathrm{~mm}^{2} / \mathrm{s}\right)$ than other benign solid tumors, such as inverted papilloma with ADC value $=1.64 \times 10^{-3} \mathrm{~mm}^{2} / \mathrm{s}$, with no statistical significant difference.

These results matched those of Sasaki et al, ${ }^{10}$ who found that there were no significant differences in the overall ADC and ADC mapping between inverted papilloma, angiofibroma, and hemangioma. Moreover, our findings matched those of Razek et $\mathrm{al}^{13}$ and Sakamoto et $\mathrm{al}^{14}{ }^{14}$ who found that angiofibroma had a higher ADC value than other solid neoplasms. This is due to excess extracellular spaces and free diffusion within vascular lesions. ${ }^{10,14}$ In addition, the perfu- sion of blood flow and susceptibility effects brought about by hemosiderin deposition may also affect ADC values.

In our study, the mean ADC value of malignant sinonasal tumors was $1.73 \times 10^{-3} \mathrm{~mm}^{2} / \mathrm{s}$ and the mean ADC value of SCC was $1.14 \times 10^{-3} \mathrm{~mm}^{2} / \mathrm{s}$, adenoid cystic carcinoma was $1.17 \times 10^{-3} \mathrm{~mm}^{2} / \mathrm{s}$, esinthoneuroblastoma was $0.95 \times 10^{-3}$ $\mathrm{mm}^{2} / \mathrm{s}$, lymphoma was $0.75 \times 10^{-3} \mathrm{~mm}^{2} / \mathrm{s}$, and malignant melanoma was $0.84 \times 10^{-3} \mathrm{~mm}^{2} / \mathrm{s}$. We found that lymphoma had lower ADC value than other malignant tumors with nonsignificant difference $(p=0.54)$.

These were similar to those mentioned by Maeda et al $^{3}$ and Sumi et al. ${ }^{11}$ They explained that DWI and ADC value were related to tumor cellularity and attributed the reduced ADC value in lymphoma to increased cellularity and reduced extracellular space.

In our study, when we used ADC value of $1.2 \times 10^{-3} \mathrm{~mm}^{2} / \mathrm{s}$ as a cut-off value for the differentiation of benign sinonasal lesions from malignant, with an accuracy rate of $90 \%, 100 \%$ sensitivity, $88.4 \%$ specificity, $77.8 \%$ PPV, and $100 \%$ NPV, we found the cut-off point to be highly statistically significant $(p=0.0001)$.

Sasaki et al ${ }^{10}$ reported an ADC cut-off point of $0.84 \times 10-3$ $\mathrm{mm}^{2} / \mathrm{s}$ was the best to distinguish benign/ inflammatory from 
malignant tumors with diagnostic ability of $61 \%$ sensitivity, 94\% specificity, 79\% accuracy, 90\% PPV, and 74\% NPV.

Razek et al ${ }^{13}$ used an ADC value of $1.53 \times 10-3 \mathrm{~mm}^{2} / \mathrm{s}$ as the threshold for differentiating malignant from benign lesions, and the best result they obtained had an accuracy of $93 \%$, sensitivity of $94 \%$, specificity of $92 \%$, PPV of $92 \%$, and NPV of $94 \%$.

White et al $^{12}$ did not use an ADC cut-off point for differentiation between benign and malignant lesions, but they found that the ADCs of the malignancies were significantly lower than the benign lesions ( $p<0.0125)$. The ADCs were inversely correlated with tumor cellularity.

In our study, the small number of lesions included in each group might affect the results. Thus, a multicenter study with large number of cases is needed.

\section{Conclusion}

When using the ADC value of $1.2 \times 10^{-3} \mathrm{~mm}^{2} / \mathrm{s}$ as a cut-off point for the differentiation between benign and malignant sinonasal lesions, we achieve $90 \%$ accuracy, 100\% sensitivity, $88.4 \%$ specificity, $77.8 \mathrm{PPV}$, and $100 \%$ NPV. At this cut-off point, benign lesions show statistically significant higher ADC value than malignant tumors.

DW, MRI, and ADC value calculations are promising quantitative methods that help distinguish between malignant and benign sinonasal lesions. They are effective methods compared with other conventional methods with short imaging time and can be easily incorporated into routine evaluations. However, further studies with a larger number of cases are needed.

Conflict of Interest and Financial Disclosure

The authors declare no financial support to this study and declare no conflict of interest.

\section{References}

1 Connor S, Hussain S, Woo E. Sinonasal imaging. Eur J Radiol 2007; 19:39-54

2 Wang J, Takashima S, Takayama F, et al. Head and neck lesions: characterization with diffusion-weighted echo-planar MR imaging. Radiology 2001;220(3):621-630

3 Maeda M, Kato H, Sakuma H, Maier SE, Takeda K. Usefulness of the apparent diffusion coefficient in line scan diffusion-weighted imaging for distinguishing between squamous cell carcinomas and malignant lymphomas of the head and neck. AJNR Am J Neuroradiol 2005;26(5):1186-1192

4 Barnes L, Brandwein M, Som PM. Diseases of the nose, paranasal sinuses, and nasopharynx,. in Barnes L (ed): Surgical Pathology of the Head and Neck (ed 2). New York, NY: Marcel Decker; 2001:439-55

5 Loevner LA, Sonners AI. Imaging of neoplasms of the paranasal sinuses. Neuroimaging Clin N Am 2004;14(4):625-646

6 Lyng H, Haraldseth O, Rofstad EK. Measurement of cell density and necrotic fraction in human melanoma xenografts by diffusion weighted magnetic resonance imaging. Magn Reson Med 2000; 43(6):828-836

7 Eggesbø HB. Radiological imaging of inflammatory lesions in the nasal cavity and paranasal sinuses. Eur Radiol 2006;16(4):872-888

8 Madani G, Beale TJ. Sinonasal inflammatory disease. Semin Ultrasound CT MR 2009;30(1):17-24

9 Schaefer PW, Grant PE, Gonzalez RG. Diffusion-weighted MR imaging of the brain. Radiology 2000;217(2):331-345

10 Sasaki M, Eida S, Sumi M, Nakamura T. Apparent diffusion coefficient mapping for sinonasal diseases: differentiation of benign and malignant lesions. AJNR Am J Neuroradiol 2011;32(6):1100-1106

11 Sumi M, Ichikawa Y, Nakamura T. Diagnostic ability of apparent diffusion coefficients for lymphomas and carcinomas in the pharynx. Eur Radiol 2007;17(10):2631-2637

12 White ML, Zhang Y, Robinson RA. Evaluating tumors and tumorlike lesions of the nasal cavity, the paranasal sinuses, and the adjacent skull base with diffusion-weighted MRI. J Comput Assist Tomogr 2006;30(3):490-495

13 Razek AA, Sieza S, Maha B. Assessment of nasal and paranasal sinus masses by diffusion-weighted MR imaging. J Neuroradiol 2009; 36(4):206-211

14 Sakamoto J, Yoshino N, Okochi K, et al. Tissue characterization of head and neck lesions using diffusion-weighted MR imaging with SPLICE. Eur J Radiol 2009;69(2):260-268 